\title{
Effect of Alpha-Linolenic Acid with Bovine Serum Albumin or Methyl-Beta-Cyclodextrin on Membrane Integrity and Oxidative Stress of Frozen-Thawed Boar Sperm
}

\author{
Won-Hee Lee ${ }^{1}$, Wook-Hwan Kim ${ }^{1}$, Hee-Tae Cheong ${ }^{2}$, Boo-Keun Yang ${ }^{1}$, and ${ }^{\dagger}$ Choon-Keun Park $^{1}$ \\ ${ }^{1}$ College of Animal Life Sciences, Kangwon National University, Chunchoen 24341, Korea \\ ${ }^{2}$ College of Veterinary Medicine, Kangwon National University, Chunchoen 24341, Korea
}

\begin{abstract}
The study was conducted to investigate the effects of alpha-linolenic acid (ALA) combined with bovine serum albumin (BSA) or methyl-beta-cyclodextrin (MBCD) on plasma and acrosomal membrane damages, mitochondrial activity, morphological abnormality, motility, and oxidative stress in frozen-thawed boar sperm. In previous our study, $3 \mathrm{ng} / \mathrm{mL}$ ALA had been shown protective effect during freezing process of boar sperm. Therefore, we used $3 \mathrm{ng} / \mathrm{mL}$ ALA in present study and ALA was combined with same molar ratio of BSA or MBCD (ALA+BSA and ALA+MBCD, respectively). To confirm the effect of two carrier proteins, same volume of BSA and MBCD without ALA were added during cryopreservation. Membrane damage, mitochondrial activity, reactive oxygen species (ROS) and lipid peroxidation (LPO) levels were measured using flow cytometry, and movement of sperm tail as motility parameter and morphological abnormality were observed under light microscope. In results, all of sperm parameters were enhanced by ALA combined with BSA or MBCD compared to control groups $(p<0.05)$. Mitochondrial activity, morphological abnormality, ROS and LPO levels in ALA+BSA or MBCD groups were no significant difference compared with ALA, BSA and MBCD treatment groups. On the other hand, plasma and acrosomal membrane intact, and sperm motility in ALA+MBCD group were higher than single treatment groups $(p<0.05)$, whereas ALA+BSA did not differ. Our findings indicate that carrier proteins such as BSA and MBCD could improve the effect of ALA during cryopreservation of boar sperm, and treatment of ALA with carrier proteins enhance membrane integrity, mitochondrial activity through reduction of ROS-induced LPO.
\end{abstract}

Key words : Boar sperm, Cryopreservation, Alpha-linolenic acid, Bovine serum albumin, Methyle-beta-cyclodextrin, Membrane potential, Oxidative stress

\section{INTRODUCTION}

One of assisted reproductive technologies (ART) in domestic animal industry, liquid- or cryo- preservation of sperm are used for artificial insemination (AI), maintenance and supply of the superior genetic resources, and decrease the possibility of diseases. In the pig industry, liquid preserved semen are commonly used, however, they are hard to keep for long time because they are exposed to various stresses such as light, temperature and chemicals that caused reduction of sperm viability and fertility (Kadirvel et al., 2009; Alkmin et al., 2014). To enhance the preservation periods of boar sperm, cryopreservation was developed and cryopreserved sperm have prolonged pre-

Manuscript received January 12, 2019, Received in revised form February 19, 2019, Accepted February 27,2019

${ }^{\dagger}$ Corresponding Author : Choon-Keun Park, College of Animal Life Sciences, Kangwon National University, Chuncheon 24341, Korea. Tel: +82-33-2508627, E-mail: parkck@kangwon.ac.kr

This is an Open Access article distributed under the terms of the Creative Commons Attribution Non-Commercial License (http:// creative-commons.org/licenses/by-nc/3.0) which permits unrestricted non-commercial use, distribution, and reproduction in any medium, provided the original work is properly cited. 
servation periods compared to liquid preserved sperm (Yoshida, 2000). Although preservation period of sperm is prolonged, spermatozoa was damaged by cold shock, oxidative stress, and ice crystal formation during freezing and thawing process, and these damages negatively influence to membrane function and structure of spermatozoa via change of ratio between phospholipid and cholesterol in plasma membrane (White, 1993; Agarwal et al., 2014; Baishya et al., 2014). Therefore, numerous researches have been carried out to reduce cryodamage by supplementation of antioxidants (Kaeoket et al., 2010), amino acids (Reddy et al., 2010) and cholesterol (Moce et al., 2010) during cryopreservation.

Because sperm membrane contains various polyunsaturated fatty acids (PUFAs), membrane integrity of spermatozoa and supplementation of fatty acid are closely associated. Safarinejad et al. (2010) had reported that concentrations of omega-3 (n-3) fatty acids including alpha-linolenic acids (ALA), eicosapentaenoic acid (EPA), and docosahexaenoic acid (DHA) in spermatozoa from fertile men were higher than sperm from infertile men, while omega-6 fatty acids were lower in sperm from fertile men. These $n$ 3 fatty acids were found in fish oil and sunflower oil that are used as one of feed composition and dietary supplement of these oil influenced to sperm characteristics. In bulls, intake of sunflower oil enhanced motility and plasma membrane integrity of frozen-thawed spermatozoa (Adeel et al., 2009). And progressive motility was increased in cooled and frozen sperm from DHA-enriched nutriceutical fed stallion compared to control diet (Brinsko et al., 2005). Rooke et al. (2001) reported that supplementation of tuna oil to boar diets increased proportion of progressively motile sperm and normal acrosome, whereas abnormal morphologies were decreased. These results demonstrated that supplement of fatty acids could improve membrane integrity, sperm motility and viability, as well as cold sensitivity.

As one of phospholipid in plasma membrane, ALA plays role as precursor of EPA and DHA, energy resource, and regulator of membrane function (Shevchenko \& Simons, 2010). In our previous study, we found that addition of $3 \mathrm{ng} / \mathrm{mL}$ of ALA in frozen extender protected ethanolmediated damages on plasma membrane and acrosome during cryopreservation of boar spermatozoa (Lee et al., 2016b). Freezing and thawing process lead to discharge phospholipid such as ALA and arachidonic acid in plasma membrane of spermatozoa and it was caused to lose the membrane function and stability. Therefore, we expected that supplementation of ALA during freezing process could reduce the membrane damages by discharging of phospholipids in plasma membrane. However, Graham \& Foote (1987) demonstrated that hydrophilic outer side of phospholipid bilayer is cause to low solubility and efficiency of lipids supplementation. For this reason, ALA was recommended to use with carrier proteins such as bovine serum albumin (BSA) and methyl-beta-cyclodextrin (MBCD). Based on these reports and our previous studies (Lee et al., 2016a; 2016b), we hypothesized that supplementation of ALA combined with carrier proteins could protect membrane damages through increasing of its solubility and efficiency during cryopreservation of boar sperm. Therefore, this study was conducted to investigate protective effect of ALA combined with BSA or MBCD on plasma and acrosomal membrane, morphology and oxidative stress in boar spermatozoa.

\section{MATERIALS AND METHODS}

\section{Sperm sample}

All procedures that involved the use of animals were approved by the Kangwon National University Institutional Animal Care and Use Committee (KIACUC-09-0139). All of boar semen were purchased from Gumbo (Wonju, Korea). The semen were collected by gloved-hand method once a week and transported to laboratory. The sperm samples with more than $75 \%$ motility and $80 \%$ viability were used for this study. 


\section{Preparation of ALA combined with BSA or MBCD}

All of reagents were purchased from Sigma-Aldrich (St. Louis, MO, USA). For supplementation of ALA into the first freezing extender, ALA was mixed with same molar ratio of BSA or MBCD. Briefly, $0.06 \mathrm{mg}$ of ALA was added to $10 \mathrm{~mL} \mathrm{BSA}$ or MBCD solution $(1.4 \mathrm{mg} / \mathrm{mL}$ and $0.028 \mathrm{mg} / \mathrm{mL}$, respectively) diluted at distilled water and each mixtures were stirred at room temperature for $1 \mathrm{~h}$. Then, $0.5 \mu \mathrm{L}$ of aliquot was supplied to $1 \mathrm{~mL}$ of first freezing extender. Based on our previous results (Lee et al., 2016b), $3 \mathrm{ng} / \mathrm{mL}$ of ALA was determined as final concentration. To clarify effect of ALA mixture, $3 \mathrm{ng} / \mathrm{mL}$ ALA and same molar ratio of $\mathrm{BSA}$ or $\mathrm{MBCD}$ was added to first freezing extender, respectively.

\section{Freezing and thawing of boar semen}

As a first freezing extender, lactose egg yolk (LEY; $11 \%[\mathrm{w} / \mathrm{v}]$ lactose and $20 \%$ [v/v] egg yolk in distilled water) was used. The boar sperm was diluted at $1.5 \times 10^{9}$ spermatozoa/mL using $1 \mathrm{~mL}$ of LEY containing ALA combined with BSA or MBCD and it was cooled down to $4{ }^{\circ} \mathrm{C}$ for $2 \mathrm{~h}$. Then, $0.5 \mathrm{~mL}$ of LEY supplemented with $9 \%$ Glycerol and 1.5\% Orvus Es Paste (OEP; Nova Chem, USA) was added to cooled sperm samples and they were injected into $0.25 \mathrm{~mL}$ straws. Filled straws were placed on $10 \mathrm{~cm}$ above liquid nitrogen $\left(\mathrm{LN}_{2}\right)$ for $10 \mathrm{~min}$, then, pre-freezing samples were immersed and preserved in $\mathrm{LN}_{2}$. To analyze sperm characteristics, cryopreserved samples were thawed at $37^{\circ} \mathrm{C}$ for $45 \mathrm{sec}$.

\section{Flow cytometry}

Flow cytometry was used to measure plasma membrane intact, acrosomal damage, mitochondrial activity, reactive oxygen species (ROS) level and lipid peroxidation in frozen-thawed boar sperm. The data from flow cytometry were obtained from total 10,000 of spermatozoa using FACsCalibur and were analyzed by CELLQuest version 6.0 .
1) Measurement of plasma membrane intact, acrosomal damage and mitochondrial activity

To measure intact of plasma membrane, 6 nM SYBR-14 was used, and $3 \mu \mathrm{M}$ Lectin from Arachis hypogagea (FITC-PNA) and $2 \mu \mathrm{M}$ Rhodamine123 were used to analyze acrosomal damage and mitochondrial activity, respectively. Frozen-thawed sperm samples were stained using each fluorescent dye at $38^{\circ} \mathrm{C}$ in dark room for $5 \mathrm{~min}$. Then, $2 \mu \mathrm{M}$ propidium iodide was added to stained samples and subsequently incubated in same condition for $5 \mathrm{~min}$.

\section{2) Intracellular ROS level in live sperm}

Intracellular ROS level in live spermatozoa was measured using $\mathrm{H}_{2}$ DCFDA (0.8 $\mu \mathrm{M}$, Molecular probes, USA). Thawed sperm was stained by $\mathrm{H}_{2}$ DCFDA at $38^{\circ} \mathrm{C}$ in dark room for $15 \mathrm{~min}$. Then, $2 \mu \mathrm{M}$ propidium iodide was added to stained samples and subsequently incubated in same condition for $5 \mathrm{~min}$.

\section{3) Lipid peroxidation (LPO) in frozen-thawed sperm}

To measure LPO level in samples, C11-BODIPY 581/591 (3.5 $\mu \mathrm{M}$, Molecular probes, USA) was added to frozenthawed boar sperm and they were incubated at $38{ }^{\circ} \mathrm{C}$ in dark room for $30 \mathrm{~min}$. Then, fluorescent intensity of stained samples were measured.

\section{Observation of tail movement}

The frozen-thawed semen was diluted at $4 \times 10^{6}$ spermatozoa/mL with modified Modena B (30 g/L glucose, 2.25 g/L EDTA, $2.5 \mathrm{~g} / \mathrm{L}$ sodium citrate, $1 \mathrm{~g} / \mathrm{L}$ sodium bicarbonate, $5.00 \mathrm{~g} / \mathrm{L}$ tris, $2.5 \mathrm{~g} / \mathrm{L}$ citric acid, $0.05 \mathrm{~g} / \mathrm{L}$ cysteine and $0.3 \mathrm{~g} / \mathrm{L}$ gentamicin sulfate). Then, $7 \mu \mathrm{L}$ of semen sample was placed onto a pre-warmed glass slide $\left(37.5^{\circ} \mathrm{C}\right)$ and it was covered by cover slip. To maintain sperm motility, samples were placed on $37.5^{\circ} \mathrm{C}$ warm stage and a total of 200 spermatozoa in randomly selected five section were observed using light microscope. The sperm with tail 
movement was decided as motile sperm.

\section{Morphological abnormality}

Rose Bengal staining was used to observe morphological abnormality of frozen-thawed boar spermatozoa. The samples were smeared on slide glass and were dehydrated at room temperature. Then, samples on slide glass were stained using 3\% (v/v) Rose Bengal solution and excessive Rose Bengal solution was removed. After dehydration of stained sperm, retained Rose Bengal was washed using water and sperm samples were dehydrated for observation. Morphological abnormality of sperm was classified by following criteria; in head:detach, big head, small head, and twin head; in middle piece:cytoplasmic droplet, folded, and absence; in tail:folded, coiled, short tail, and absence. The sperm with abnormal morphology were observed under a light microscopic at $\times 400$ magnification and a total of 200 spermatozoa in randomly selected five section were counted.

\section{Statistical analysis}

Data were analyzed using Statistical Analysis System software (SAS ${ }^{\circledR}$ version 9.4, Cary, NC, USA). All data were analyzed using general linear model (GLM) and treatment groups were compared for differences though use of Dun- can's modified multiple range test $(p<0.05)$.

\section{RESULTS}

\section{Effect of ALA combined with BSA or MBCD on} plasma and acrosomal membrane damage, mitochondrial activity and morphological abnormality

Changes of membrane integrity, mitochondrial activity and morphologically abnormal sperm were presented in Table 1. Both of carrier proteins combined with ALA enhanced plasma membrane intact and mitochondrial activity, and reduced acrosomal membrane damage and sperm abnormalities compared to control group $(p<0.05)$. In particular, treatment of ALA combined with MBCD improved plasma and acrosomal membrane potential compared with single treatment of ALA, BSA and MBCD $(p<0.05)$. Interestingly, acrosomal damage was decreased by ALA and carrier proteins regardless of combination $(p<0.05)$.

2. Changes of motility and oxidative stress by ALA combined with BSA or MBCD

Effect of ALA combined with BSA or MBCD on motility and oxidative stress status in frozen-thawed boar sperm were showed in Fig. 1 and 2, respectively. The ratio of sperm with tail movement in ALA combined with both

Table 1. Effects of alpha-linolenic acid (ALA) with or without bovine serum albumin (BSA) or methyl-betacyclodextrin (MBCD) on membrane damages and morphology of frozen-thawed boar sperm

\begin{tabular}{|c|c|c|c|c|c|c|}
\hline \multirow{2}{*}{ Parameters (\%) } & \multicolumn{6}{|c|}{ Treatment groups } \\
\hline & Control & ALA & BSA & MBCD & $\mathrm{ALA}+\mathrm{BSA}$ & $\mathrm{ALA}+\mathrm{MBCD}$ \\
\hline Plasma membrane intact & $58.29 \pm 1.54^{\mathrm{a}}$ & $51.21 \pm 1.1^{\mathrm{ab}}$ & $60.99 \pm 1.17^{\mathrm{ab}}$ & $60.88 \pm 1.71^{\mathrm{ab}}$ & $64.09 \pm 1.71^{\mathrm{bc}}$ & $65.67 \pm 0.95^{c}$ \\
\hline Acrosomal damage & $18.54 \pm 0.70^{\mathrm{a}}$ & $15.09 \pm 0.71^{\mathrm{b}}$ & $15.25 \pm 0.69^{\mathrm{b}}$ & $15.50 \pm 0.35^{\mathrm{b}}$ & $14.51 \pm 0.62^{\mathrm{bc}}$ & $13.10 \pm 0.70^{c}$ \\
\hline Mitochondrial activity & $55.87 \pm 2.35^{\mathrm{a}}$ & $61.12 \pm 1.46^{\mathrm{ab}}$ & $60.84 \pm 2.29^{\mathrm{ab}}$ & $60.76 \pm 2.32^{\mathrm{ab}}$ & $62.59 \pm 1.70^{\mathrm{b}}$ & $63.01 \pm 1.26^{\mathrm{b}}$ \\
\hline Morphological abnormality & $27.05 \pm 5.36^{\mathrm{a}}$ & $19.20 \pm 2.70^{\mathrm{ab}}$ & $22.26 \pm 1.04^{\mathrm{ab}}$ & $22.50 \pm 0.81^{\mathrm{ab}}$ & $16.60 \pm 1.10^{\mathrm{b}}$ & $13.90 \pm 0.70^{\mathrm{b}}$ \\
\hline
\end{tabular}

${ }^{\mathrm{a}-\mathrm{c}}$ Mean values with different superscripts are significantly difference within same rows $(p<0.05)$.

Control, without ALA, BSA, and MBCD; ALA, with 3 ng/mL ALA; BSA, with $0.7 \mu \mathrm{g} / \mathrm{mL}$ BSA; MBCD, with 14 ng/mL MBCD; ALA+BSA, with $3 \mathrm{ng} / \mathrm{mL}$ ALA and $0.7 \mu \mathrm{g} / \mathrm{mL}$ BSA; ALA+MBCD, with $3 \mathrm{ng} / \mathrm{mL}$ ALA and $14 \mathrm{ng} / \mathrm{mL} \mathrm{MBCD}$. 


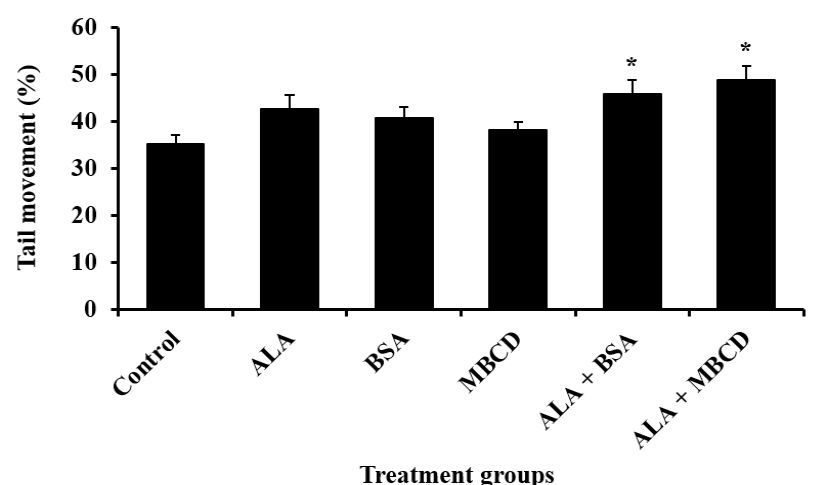

Fig. 1. Effect of alpha-linolenic acid (ALA; $3 \mathrm{ng} / \mathrm{mL}$ ) combined with bovine serum albumin (BSA; 0.7 $\mu \mathrm{g} / \mathrm{mL}$ ) or methyl-beta-cyclodextrin (MBCD; 14 $\mathrm{ng} / \mathrm{mL}$ ) during freezing on mobility of frozenthawed boar sperm. Asterisks indicate significant difference in treatment groups compared with control $(p<0.05)$. All data were presented as mean \pm SEM from 6 repeated experiments.

of carrier proteins were higher than control $(p<0.05)$. Both of live sperm with high level of ROS and LPO were reduced by supplementation of ALA combined with both of BSA and MBCD compared to control group $(p<0.05)$.

\section{DISCUSSION}

This study was conducted to confirm effect of ALA combined with carrier proteins during cryopreservation on membrane damage, morphological abnormality, motility and oxidative stress status of boar sperm. The findings in this study show that 1) ALA combined with BSA and MBCD during cryopreservation reduced plasma and acrosomal membrane damages, and 2) reduced membrane damage improved mitochondrial activity, morphological intact and motility. Finally, 3) treatment of ALA combined with carrier proteins could decreased LPO derived from ROS generation.

As one of detrimental factor during freezing of spermatozoa, change of membrane structure is occurred by redistribution of lipids and proteins in sperm plasma membrane during cooling process at from $22^{\circ} \mathrm{C}$ to $1{ }^{\circ} \mathrm{C}$ (Parks \&

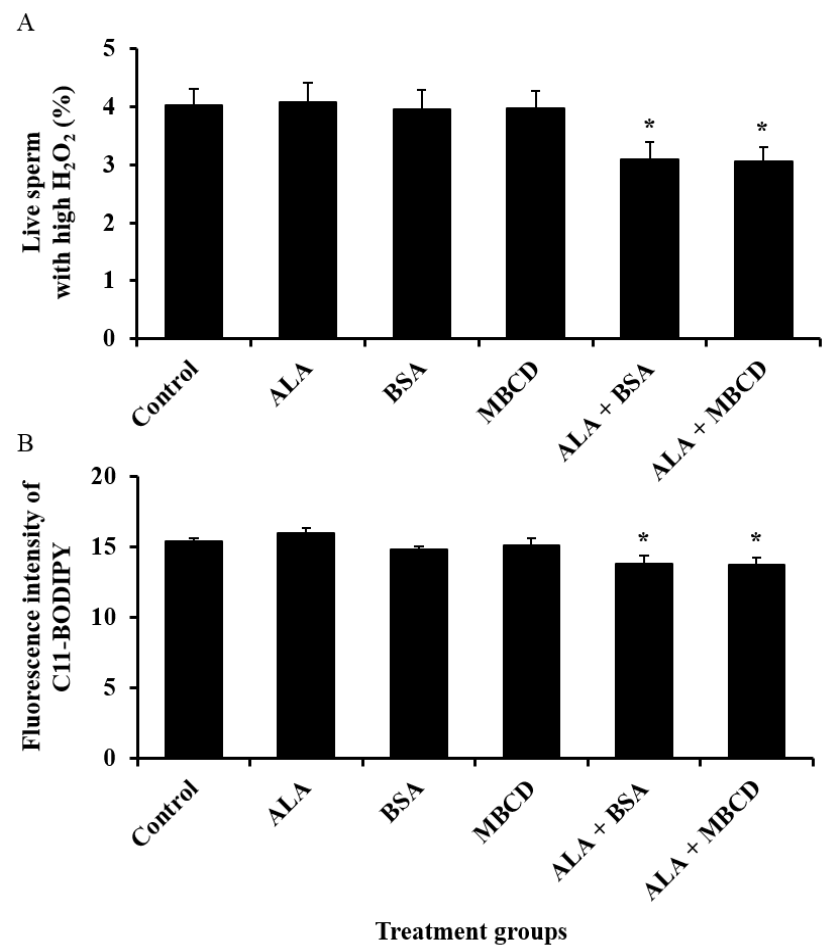

Fig. 2. Changes of $\mathrm{H}_{2} \mathrm{O}_{2}$ levels in live sperm and fluorescence intensity of C11-BODIPY (lipid peroxidation) in frozen-thawed boar sperm by 3 $\mathrm{ng} / \mathrm{mL}$ alpha-linolenic acid (ALA) with or without $0.7 \mu \mathrm{g} / \mathrm{mL}$ bovine serum albumin (BSA) and $14 \mathrm{ng} / \mathrm{mL}$ methyl-beta-cyclodextrin (MBCD) during freezing process. Asterisks indicate significant difference in treatment groups compared with control $(p<0.05)$. All data were presented as mean \pm SEM from 3 repeated experiments.

Graham, 1992). During the temperature change, fatty acids that caused to reduce membrane fluidity and permeability are released from plasma membrane (Watson, 2000). Kaka et al. (2015) reported that supplementation of ALA with ethyl alcohol during cryopreservation of bull sperm increased ALA concentration in spermatozoa and improved motility, membrane and acrosome integrity, and viability. However, because outer side of plasma membrane have hydrophilic property, fatty acids including ALA is hard to pass through membrane. Therefore, carrier proteins such as BSA and MBCD are commonly used to enhance efficiency of fat-soluble substrates in various researches. The BSA 
combined with oleic and linoleic acids promoted growth activity of human diploid fibroblasts (Kan \& Yamane, 1982) and supplementation of cyclodextrin combined fatsoluble substrates including cholesterol and vitamin E improved quality of frozen-thawed ram sperm (Benhenia et al., 2016; Benhenia et al., 2018).

Both of plasma membrane and mitochondria of spermatozoa play a crucial roles in motility, fluidity and viability, however, they were damaged by a variety of damages that are occurred during freezing and thawing process (Watson, 2000). In particular, mitochondria is involved in production of energy and movement of sperm flagellum (Cardullo \& Baltz, 1991). Their functions are closely related to sperm motility and motility of sperm is important parameter for quality because sperm with high motility has a high probability of fertilization with oocyte (Talevi et al., 2013). Therefore, reduction of damage on plasma membrane and mitochondria is most important to maintain the sperm viability, motility and function, and a variety of substrates such as fatty acids, saccharides and antioxidants were added to freezing extender for reduction of cryo-stress (Pena et al., 2003; Bucak et al., 2007; Kaka et al., 2015). In present study, supplementation of ALA combined with BSA and MBCD enhanced the plasma membrane intact, mitochondrial activity and sperm motility, whereas single treatment of ALA, BSA and MBCD did not affect compared to control group. These results were corresponded to our previous results that treatment of diluted ALA using $0.1 \%$ BSA increased viability and mitochondrial intact of frozen-thawed boar spermatozoa compared to non-treated group, however, individual treatment did not differ (Lee et al., 2016a). The addition of n-3 ALA to extender elevated PUFA content of sperm membrane and this led to improve the fluidity of sperm membrane and increase sperm motility (Towhidi \& Parks, 2012). Thus, we expected that treatment of ALA with carrier proteins could enhanced effect of fatty acid on function and motility of spermatozoa via increasing absorption into plasma membrane surrounding the spermatozoa including head, middle piece and tail. However, ALA concentration in sperm by using of carrier proteins is needed to measure.

The ice crystal formation during cryopreservation of sperm is one of detrimental factors of changes of membrane composition including re-aggregation of phospholipids and redistribution of the membrane domain (Muller et al., 2008). These changes in sperm membrane led to alteration of membrane permeability, intracellular calcium concentration and morphology (Parks \& Lynch, 1992). Especially, intact plasma membrane in spermatozoa is important for maintenance of their morphology and efflux of phospholipids in plasma membrane during cryopreservation is caused the morphological abnormalities (Brinsko et al., 2005). In our present findings, morphologically abnormality sperm in ALA with both of carrier proteins groups were lower than control group and it was corresponded with result of plasma membrane intact. In bull, treatment of ALA during freezing process increased ratio of normal morphology of spermatozoa after thawing and these tendency of morphological results was corresponded with results in membrane integrity and motility (Kaka et al., 2015). Therefore, these results suggest that supplementation of ALA with BSA or MBCD could replace released phospholipids from plasma membrane, and it contributed stabilization of membranes integrity and structure against cold shock.

Acrosome reaction is an essential phenomenon for penetration of sperm into the oocyte and acrosome reacted sperm before access to oocytes lost their fertility and viability (Bleil et al., 1988). Because the first step of acrosome reaction is fusion of plasma and acrosomal membrane, maintenance of membrane integrity in spermatozoa is closely associated with prevention of early acrosome reaction. It is induced by various physical and chemical stress such as ROS generation, ice crystal formation and osmotic pressure (Lamirande et al., 1998). In this present study, acrosomal damage was decreased by ALA, BSA 
and $\mathrm{MBCD}$ regardless of complex treatment, in particular, ALA combined with MBCD showed lowest acrosomal damage. These results was similar to our previous study that treatment of ALA, BSA and ALA diluted by BSA reduced acrosome reacted sperm (Lee et al., 2016a). These our results showed that acrosomal membrane was more sensitively affected to ALA and carrier proteins than plasma membrane and mitochondrial activity.

Because plasma membrane of boar spermatozoa contains higher concentration of PUFAs than other species, they are more sensitive to damage from ROS and ROSinduced LPO (Tavilani et al., 2006). The efflux of PUFAs from plasma membrane is caused to ROS generation and LPO, and induced LPO repeatedly effuse fatty acids in plasma membrane though activation of phospholipase A2 (Wathes et al., 2007). These efflux of fatty acids, generation ROS and LPO lead to damage on mitochondrial membrane and DNA, loss of motility, acrosome integrity and viability (Schiller et al., 2000; O'Connell et al., 2002; Kadirvel et al., 2009). Kaka et al. (2015) reported that malondialdehyde levels in frozen-thawed bull sperm that is used for measurement of LPO were dose-dependently increased by ALA diluted with ethanol and this results indicated that high concentration of ALA during cryopreservation of sperm could induce LPO. In our findings, intracellular $\mathrm{H}_{2} \mathrm{O}_{2}$ level in live sperm and LPO were decreased by ALA combined with both of BSA and MBCD compared to non-treated group. We used final concentration of $3 \mathrm{ng} / \mathrm{mL}$ ALA in this study, and expected that this ALA concentration did not induced LPO in frozen-thawed boar sperm. Therefore, these results suggest that low concentration of ALA with carrier proteins could reduce ROS generation and ROS-induced LPO without increasing of LPO through stabilization of plasma membrane.

In conclusion, we found that treatment of ALA combined with carrier proteins during cryopreservation enhanced plasma and acrosomal membrane intact, mitochondrial activity, motility, and morphology, and reduced intra- cellular ROS and LPO levels in frozen-thawed boar spermatozoa. These findings suggest that carrier proteins such as BSA and MBCD could enhanced efficiency of ALA during freezing process of sperm, and ALA combined carrier proteins could protect membrane and functional integrity of sperm, and morphology through reduction of ROS generation and LPO by stabilization of plasma membrane.

\section{ACKNOWLEDGEMENTS}

This study has been worked with the support of a research grant of Kangwon National University in 2018.

\section{REFERENCES}

Adeel M, Ijaz A, Aleem M, Rehman H, Yousaf MS, Jabbar MA (2009) Improvement of liquid and frozen-thawed semen quality of Nili-Ravi buffalo bulls (Bubalus bubalis) through supplementation of fat. Theriogenology 71:1220-1225.

Agarwal A, Virk G, Ong C, du Plessis SS (2014) Effect of oxidative stress on male reproduction. World J Mens Health 32:1-17.

Alkmin DV, Perez-Patino C, Barranco I, Parrilla I, Vazquez JM, Martinez EA, Rodriguez-Martinez H, Roca J (2014) Boar sperm cryosurvival is better after exposure to seminal plasma from selected fractions than to those from entire ejaculate. Cryobiology 69:203-210.

Baishya SK, Biswas RK, Kadirvel G, Deka BC, Kumar S, Sinha S, Dutta DJ, Saikia GK (2014) Effect of conventional and controlled freezing method on the post thaw characteristics of boar spermatozoa. Anim Reprod Sci 149:231-237.

Benhenia K, Lamara A, Fatmi S, Iguer-Ouada M (2016) Effect of cyclodextrins, cholesterol and vitamin $\mathrm{E}$ and their complexation on cryopreserved epididymal ram semen. Small Rumin Res 141:29-35.

Benhenia K, Rahab H, Smadi MA, Benmakhlouf H, La- 
mara A, Idres T, Iguer-Ouada M (2018) Beneficial and harmful effects of cyclodextrin-vitamin E complex on cryopreserved ram sperm. Anim Reprod Sci 195:266273.

Bleil JD, Greve JM, Wassarman PM (1988) Identification of a secondary sperm receptor in the mouse egg zona pellucida: Role in maintenance of binding of acrosome-reacted sperm to eggs. Dev Biol 128:376-385.

Brinsko SP, Varner DD, Love CC, Blanchard TL, Day BC, Wilson ME (2005) Effect of feeding a DHA-enriched nutriceutical on the quality of fresh, cooled and frozen stallion semen. Theriogenology 63:1519-1527.

Bucak MN, Atessahin A, Varisli O, Yuce A, Tekin N, Akcay A (2007) The influence of trehalose, taurine, cysteamine and hyaluronan on ram semen microscopic and oxidative stress parameters after freeze-thawing process. Theriogenology 67:1060-1067.

Cardullo RA, Baltz JM (1991) Metabolic regulation in mammalian sperm: Mitochondrial volume determines sperm length and flagellar beat frequency. Cell Motil Cytoskel 19:180-188.

Graham JK, Foote RH (1987) Effect of several lipids, fatty acyl chain length, and degree of unsaturation on the motility of bull spermatozoa after cold shock and freezing. Cryobiology 24:42-52.

Kadirvel G, Kumar S, Kumaresan A (2009) Lipid peroxidation, mitochondrial membrane potential and DNA integrity of spermatozoa in relation to intracellular reactive oxygen species in liquid and frozen-thawed buffalo semen. Anim Reprod Sci 114:125-134.

Kaeoket K, Chanapiwat P, Tummaruk P, Techakumphu M (2010) Supplemental effect of varying L-cysteine concentrations on the quality of cryopreserved boar semen. Asian J Androl 12:760-765.

Kaka A, Wahid H, Rosnina Y, Yimer N, Khumran AM, Behan AA, Ebrahimi M (2015) Alpha-linolenic acid supplementation in tris extender can improve frozenthawed bull semen quality. Reprod Domest Anim
50:29-33.

Kaka A, Wahid H, Rosnina Y, Yimer N, Khumran AM, Sarsaifi K, Behan AA, Kaka U, Ebrahimi M (2015) $\alpha$ Linolenic acid supplementation in BioXcell ${ }^{\circledR}$ extender can improve the quality of post-cooling and frozenthawed bovine sperm. Anim Reprod Sci 153:1-7.

Kan M, Yamane I (1982) In vitro proliferation and lifespan of human diploid fibroblasts in serum-free BSA-containing medium. J Cell Physiol 111:155-162.

de Lamirande E, Tsai C, Harakat A, Gagnon C (1998) Involvement of reactive oxygen species in human sperm arcosome reaction induced by A23187, lysophosphatidylcholine, and biological fluid ultrafiltrates. J Androl 19:585-594.

Lee WH, Hwangbo Y, Lee SH, Cheong HT, Yang BK, Park CK (2016a) Effects of $\alpha$-linolenic acid and bovine serum albumin on frozen-thawed boar sperm quality during cryopreservation. Reprod Dev Biol 40:33-37.

Lee WH, Hwangbo Y, Lee SH, Yang JW, Kim HY, Lee YR, Park JE, Cheong HT, Yang BK, Park CK (2016b) Effects of alpha-linolenic acid in frozen-thawed boar spermatozoa. Reprod Dev Biol 40:27-31.

Muller K, Muller P, Pincemy G, Kurz A, Labbe C (2008) Characterization of sperm plasma membrane properties after cholesterol modification: Consequences for cryopreservation of rainbow trout spermatozoa. Biol Reprod 78:390-399.

O'Connell M, McClure N, Lewis SEM (2002) The effects of cryopreservation on sperm morphology, motility and mitochondrial function. Hum Reprod 17:704-709.

Parks JE, Graham JK (1992) Effects of cryopreservation procedures on sperm membranes. Theriogenology 38 : 209-222.

Parks JE, Lynch DV (1992) Lipid composition and thermotropic phase behavior of boar, bull, stallion, and rooster sperm membranes. Cryobiology 29:255-266.

Pena FJ, Johannisson A, Wallgren M, Rodriguez Martinez $\mathrm{H}$ (2003) Antioxidant supplementation in vitro im- 
proves boar sperm motility and mitochondrial membrane potential after cryopreservation of different fractions of the ejaculate. Anim Reprod Sci 78:85-98.

Rooke JA, Shao CC, Speake BK (2001) Effects of feeding tuna oil on the lipid composition of pig spermatozoa and in vitro characteristics of semen. Reproduction $121: 315-322$.

Safarinejad MR, Hosseini SY, Dadkhah F, Asgari MA (2010) Relationship of omega-3 and omega-6 fatty acids with semen characteristics, and anti-oxidant status of seminal plasma: A comparison between fertile and infertile men. Clin Nutr 29:100-105.

Schiller J, Arnhold J, Glander HJ, Arnold K (2000) Lipid analysis of human spermatozoa and seminal plasma by MALDI-TOF mass spectrometry and NMR spectroscopy - effects of freezing and thawing. Chem Phys Lipids 106:145-156.

Shevchenko A, Simons K (2010) Lipidomics: Coming to grips with lipid diversity. Nat Rev Mol Cell Biol 11: 593-598.

Reddy NSS, Mohanarao GJ, Atreja SK (2010) Effects of adding taurine and trehalose to a tris-based egg yolk extender on buffalo (Bubalus bubalis) sperm quality following cryopreservation. Anim Reprod Sci 119:183190.
Talevi R, Barbato V, Fiorentino I, Braun S, Longobardi S, Gualtieri R (2013) Protective effects of in vitro treatment with zinc, d-aspartate and coenzyme q10 on human sperm motility, lipid peroxidation and DNA fragmentation. Reprod Biol Endocrinol 11:81.

Tavilani H, Doosti M, Abdi K, Vaisiraygani A, Joshaghani HR (2006) Decreased polyunsaturated and increased saturated fatty acid concentration in spermatozoa from asthenozoospermic males as compared with normozoospermic males. Andrologia 38:173-178.

Towhidi A, Parks JE (2012) Effect of n-3 fatty acids and $\alpha$ tocopherol on post-thaw parameters and fatty acid composition of bovine sperm. J Assist Reprod Genet 29: 1051-1056.

Wathes DC, Abayasekara DRE, Aitken RJ (2007) Polyunsaturated fatty acids in male and female reproduction. Biol Reprod 77:190-201.

Watson PF (2000) The causes of reduced fertility with cryopreserved semen. Anim Reprod Sci 60:481-492.

White IG (1993) Lipids and calcium uptake of sperm in relation to cold shock and preservation: A review. Reprod Fertil Dev 5:639-658.

Yoshida M (2000) Conservation of sperms: Current status and new trends. Anim Reprod Sci 60:349-355. 